\title{
Kinesiology Tape: A Descriptive Survey of Healthcare Professionals in the United States
}

\author{
Scott W Cheatham, Ph.D., DPT, PT, OCS, ATC, CSCS ${ }^{1}$, Russell T Baker, PhD, DAT, AT, CMP, PRT-C® ${ }^{2}$, Thomas E \\ Abdenour, DHSc, ATC, CES $^{3}$ \\ ${ }^{1}$ California State University Dominguez Hills, 2 University of Idaho, ${ }^{3}$ Abdenour Consulting \\ Keywords: recovery, perceived pain, muscle soreness \\ https://doi.org/10.26603/001c.22136
}

\section{International Journal of Sports Physical Therapy}

Vol. 16, Issue 3, 2021

\section{Background}

The existing body of kinesiology tape (KT) research reveals inconsistent results which challenges the efficacy of the intervention. Understanding professional beliefs and KT clinical application might provide insight for future research and development of evidence-based guidelines.

\section{Purpose}

The purpose of this study was to survey and document the beliefs and clinical application methods of KT among healthcare professionals in the United States.

\section{Design}

Cross-sectional survey study.

\section{Methods}

A 30-question online survey was emailed to members of the National Athletic Trainers Association, Academy of Orthopedic Physical Therapy, and American Academy of Sports Physical Therapy. Professionals were also informed through a recruitment post in different private healthcare Facebook groups.

\section{Results}

One thousand and eighty-three respondents completed the survey. Most respondents used KT for post-injury treatment (74\%), pain modulation (67\%), and neuro-sensory feedback (60\%). Most believed that KT stimulates skin mechanoreceptors (77\%), improve local circulation (69\%), and modulates pain (60\%). Some respondents believed KT only created a placebo effect (40\%) and use it for such therapeutic purposes (58\%). Most used a standard uncut roll (67\%) in black (71\%) or beige (66\%). Most respondents did not use any specialty pre-cut tape (83\%), infused tape (99.54\%), or a topical analgesic with tape (65\%). The most common tape tension lengths used by respondents were $50 \%$ tension (47\%) and 25\% (25\%) tension. Patient reported outcomes (80\%) were the most common clinical measures. Most respondents provided skin prep (64\%) and tape removal (77\%) instructions. Some did not provide any skin prep (36\%) or tape removal (23\%) instruction. The average recommended times to wear KT were two to three days (60\%). The maximum times ranged from two to five days (81\%).

\section{Conclusion}

This survey provides insight into how professionals use KT and highlights the gap

\footnotetext{
Corresponding Author:

Scott W. Cheatham

Associate Professor

California State University Dominguez Hills

1000 E. Victoria Street, Carson, California 90747

Scheatham@csudh.edu
} 
between research and practice. Future research should address these gaps to better determine evidence-based guidelines.

\section{Level of Evidence}

\section{INTRODUCTION}

Dr. Kenso Kase introduced kinesiology tape (KT) in the 1970s and healthcare professionals have since made it a popular intervention across different rehabilitation, fitness, and sports settings. ${ }^{1}$ The tape is made of a cotton-base, with elastic properties and adhesive which allows it to be applied directly to the skin. KT is available in different sizes, widths, material, lengths (e.g. precut, rolls), and textures. Currently, numerous manufacturers, such as KT Tape ${ }^{\circledR}, \mathrm{Ki}-$ nesio Tape ${ }^{\circledR}$, and TheraBand ${ }^{\circledR}$ Kinesiology Tape, produce various types of tape to meet different therapeutic needs such as: sports, edema control, and neurosensory effects. Some manufacturers have expanded beyond tape production and provide professional continuing education and certification to practitioners who want to utilize KT in clinical practice.

Despite the popularity, the research regarding KT therapeutic benefits is inconclusive with many studies reporting inconsistent outcomes. ${ }^{2}$ Since 2010 , approximately thirtyeight KT systematic reviews have been published appraising the efficacy for specific conditions. The reviews found inconclusive evidence for shoulder, ${ }^{3,4}$ knee, ${ }^{5}$ and elbow disorders, ${ }^{6}$ as well as spinal pain, ${ }^{7}$ proprioception, ${ }^{8}$ brachial plexus injury in children, ${ }^{9}$ muscle strength, ${ }^{10}$ and sports performance. ${ }^{11}$ Researchers also appraised the KT literature on musculoskeletal conditions, ${ }^{2,12-15}$ chronic musculoskeletal pain, ${ }^{16,17}$ sports injuries, ${ }^{18}$ in eight systematic reviews and found inconclusive results. Weak to moderate evidence was found supporting the efficacy of KT for postmastectomy lymphedema, ${ }^{19}$ children with Cerebral Palsy, ${ }^{20-22}$ stroke patients, ${ }^{23-26}$ ankle function, ${ }^{27}$ athletic performance, ${ }^{28,29}$ myofascial pain, 30 and as an adjunct therapy for shoulder impingement, ${ }^{31}$ lumbosacral pain, ${ }^{17,32-37}$ and patellofemoral pain. ${ }^{38}$

The variable KT research has left many unanswered questions regarding therapeutic efficacy, which is exacerbated by variations in KT application and use, as well as a lack of translation from the research to practice. Currently, little is known regarding the training and practice patterns of professionals who utilize KT and how practice patterns correspond to application methods used in KT research. Professionals may disregard the weak body of KT evidence given individual practice experiences with the technique. Further, evidence-based practice recommendations for application are lacking and clinicians may use their own preferred methods of administering the intervention. Variations from practice to research, or across groups of clinicians with varied training, may result in inconsistencies and limit the ability to create best practice consensus or optimal guidelines for practice and research. Thus, there is a need to survey and document the KT beliefs, training, and clinical practices of healthcare professionals to understand how KT is used for patient care. To our knowledge, KT surveys examining practice patterns, perceptions, and training of professionals utilizing the technique have not been published. Obtaining such information may help guide future studies and the development of evidence-based guidelines. The purpose of this study was to survey and document the beliefs and clinical practices of KT among healthcare professionals in the United States.

\section{METHODS}

\section{STUDY TYPE AND PARTICIPANTS}

This cross-sectional survey study was approved by the Institutional Review Board at California State University Dominguez Hills (\# 20-115). Healthcare professionals were recruited via convenience sampling between March to May 2020. Emails were sent to a random sample of members from the National Athletic Trainers Association $(\mathrm{N}=3,000)$ and all members of the Academy of Orthopedic Physical Therapy $(\mathrm{N}=17,811)$ and American Academy of Sports Physical Therapy $(\mathrm{N}=6,597)$. This sampling technique has been used in prior myofascial intervention survey research. 39,40 Healthcare professionals $(\mathrm{N}=21,775)$ were also informed through a recruitment post in different private healthcare Facebook groups. Prior research has documented that Facebook is an effective recruitment tool for healthcare research purposes. $^{41}$

\section{SURVEY DESIGN}

The online survey (SurveyMonkey ${ }^{\circledR}$ www.surveymonkey.com) included one respondent consent question and 29 questions that represented seven distinct areas:1) respondent demographics, 2) clinical perceptions about KT, 3) clinical application of standard, specialty, infused KT, topicals, and clinical measures, and 4) KT education, and referral.

The focus of respondent demographic questions was to document participant age, credentials, practice setting/s, and professional experience. The goal of clinical perceptions about KT questions were to document professional beliefs about the use of the tape with clients, KT therapeutic effects, and physiological mechanisms. Also, to document respondent beliefs about KT precautions and contraindications. The focus of the clinic application of KT questions were to document how professionals use different KT tapes, topicals, and clinical measures in their practice. Practice patterns were further assessed by documenting how professionals approached KT education such as skin prep, tape removal, length of time to wear KT, patient education, and referral.

After initial survey development was completed, the first survey draft underwent two rounds of pilot testing with four independent athletic training and physical therapy professionals to establish face validity. Based upon reviewer feedback, revisions were made, and a final set of survey items was identified. ${ }^{39,40}$ The final survey was further tested for 
readability using the Flesch reading-ease test and FleschKincaid grade level test. The 30 questions in the final survey scored 53.2 on the Flesch Ease of Reading Test and 7.0 on the Flesch-Kincaid Grade level test, which indicated the English used in the survey was fairly easy to read at the $7^{\text {th }}$ grade level. ${ }^{42}$ These methods have been used in prior myofascial intervention survey research. $39,40,43$

\section{DATA ANALYSIS}

Data were downloaded from SurveyMonkey for analysis. Statistical analysis was performed using SPSS version 25.0 (IBM SPSS, Armonk, NY, USA). Descriptive data including total responses, frequency count, and percentages were calculated. Data were treated conservatively, any respondent who failed to answer an item was removed from the data set.

\section{RESULTS}

A total of 51,000 healthcare professionals were recruited. A total of 1,535 professionals began the survey. Incomplete surveys were eliminated from the data synthesis. A total of 1083 respondents finished the survey resulting in a $2.1 \%$ completion rate $(1,083 / 51,000)$.

This section details most respondent answers for questions within the seven distinct survey areas using rounded values for ease of interpretation. A more detailed description of respondent answers can be found in Tables 1-7.

\section{RESPONDENT DEMOGRAPHICS}

Forty-five percent $(\mathrm{n}=492)$ of respondents were men and $54 \%(n=584)$ were women. Sixty-one percent $(n=657)$ reported being a physical therapist, $30 \%(n=325)$ a certified athletic trainer, $4 \%(\mathrm{n}=44)$ a physical therapist assistant, $2 \%$ $(\mathrm{n}=19)$ a chiropractor, $1 \%(\mathrm{n}=10)$ a massage therapist, and $2 \%$ reported being a member of another profession. A substantial proportion of respondents reported working in a private outpatient facility $(42 \%, \mathrm{n}=152)$, hospital based facility $(18 \%, \mathrm{n}=197)$, university sports medicine or athletic training facility $(12 \%, \mathrm{n}=131)$, and secondary school setting $(11 \%, n=125)$. The reported average years in practice was approximately 16 years (Table 1 ).

Respondent also indicated several factors that influenced how KT was applied in their clinical practice. The most common influential factors were collaboration with other professionals $(75 \%, \mathrm{n}=812)$, continuing education courses or conferences $(74 \%, \mathrm{n}=805)$, prior empirical experience $(64 \%, n=694)$, and peer review research and textbooks $(53 \%$, $\mathrm{n}=580$ ). Respondents also reported relying on websites, social media, and YouTube $(31 \%, \mathrm{n}=338)$ and manufacturer instructions $(29 \%, n=313)$ to inform their clinical application of KT (Table 2).

Several potential therapeutic effects of KT were also reported by the respondents. Most respondents believed KT modulates pain $(70 \%, \mathrm{n}=756)$, enhances proprioception and kinesthetic sense $(69 \%, n=748)$, and increases local circulation $(65 \%, n=709)$, while a smaller portion reported believing KT enhances myofascial mobility $(29 \%, n=319)$. A substantial percentage $(58 \%, \mathrm{n}=635)$ of respondents also in- dicated a belief that KT creates a placebo effect (Table 2).

The reported potential physiological mechanisms that occur with KT application are reported in Table 2. Most respondents believed that KT stimulates skin mechanoreceptors increasing proprioception $(77 \%, \mathrm{n}=834)$, lifts the skin to improve local circulation $(69 \%, n=749)$, stimulates skin nociceptors resulting in pain modulation $(60 \%, n=652)$, and creates a placebo effect $(74 \% ; n=798)$. Others indicated that KT application improves muscle activation and motor control $(46 \%, \mathrm{n}=501)$ and inhibits muscle activation (32\%, $\mathrm{n}=345$ ) when used in patient care (Table 2).

Most respondents believed their preferred tension length created a therapeutic effect by enhancing proprioception and kinesthetic sense (59\%, $\mathrm{n}=636)$, modulating pain $(55 \%$, $n=599)$, increasing local circulation (43\%, $n=469)$, and enhancing myofascial mobility $(23 \%, \mathrm{n}=254)$. Forty-four percent $(n=475)$ of respondents believed their preferred tension length provided a placebo effect (Table 2).

A large portion of respondents $(51 \%, n=549)$ considered skin irritation and itching as precautions. Twenty-five percent $(n=276)$ also considered thin skin as a precaution followed by impaired or altered sensation $(9 \%, n=87)$. Ninetyfive percent $(n=1028)$ of respondents reported no other precautions to consider beyond the ones listed in the survey (Table 2).

Regarding KT contraindications, thirty-three percent $(n=361)$ of respondents considered skin allergies (e.g. adhesives, latex) and $33 \%(n=356)$ considered open wounds and lesions as contraindications. Thirteen percent $(n=146)$ considered inability to communicate as a contraindication followed by deep vein thrombosis $(5 \%, n=52)$, undiagnosed rash or skin irritation $(4 \%, n=40)$, malignancy (active) $(3 \%$, $\mathrm{n}=38)$, and diabetes $(2 \%, \mathrm{n}=26)$. Eighty-five percent $(\mathrm{n}=918)$ of respondents reported no other contraindications to consider beyond the ones listed in the survey (Table 2).

\section{CLINICAL APPLICATION OF STANDARD KT, INFUSED KT, TOPICALS, AND CLINICAL MEASURES}

Respondents reported utilizing a variety of tape brands and styles in clinical practice (Table 3). For commercial brand KT, KT Tape ${ }^{\circledR}(59 \%, \mathrm{n}=640)$, RockTape ${ }^{\circledR}(50 \% \mathrm{n}=546)$, Kinesio ${ }^{\circledR}$ tape $(33 \%, n=359)$, and TheraBand ${ }^{\circledR}$ tape $(11 \%, n=116)$ were the most commonly reported types of tape used by respondents. The respondents also indicated using a variety of tape colors, with black $(71 \%, \mathrm{n}=774)$ and beige $(66 \%$, $\mathrm{n}=713$ ) being the most common colors used (Table 3).

Most respondents reported using the KT standard uncut roll $(2 \mathrm{in} / 5 \mathrm{~cm} \times 16.4 \mathrm{ft} / 5 \mathrm{~m})(67 \%, \mathrm{n}=724)$, while the large standard uncut roll (36\%, $\mathrm{n}=389)$, standard pre-cut strips $(15 \% \mathrm{n}=168)$, and the wide uncut roll $(11 \%, \mathrm{n}=114)$ were also commonly used by clinicians (Table 3). Only a small portion of respondents reported using the pre-cut fan tape $(9 \%$, $\mathrm{n}=96)$, pre-cut tape for the lower body $(4 \%, \mathrm{n}=43)$, or precut tape for the upper body ( $3 \% \mathrm{n}=38)$; most of the respondents $(83 \%, n=902)$ reported not using any of the specialty pre-cut tape options available (Table 3 ).

When applying KT to clients, the most common tension length used by respondents was $50 \%(47 \%, n=510)$ followed by $25 \%(25 \%, n=268)$ and $75 \%(18 \%, n=199)$ tension; seven percent $(n=71)$ of respondents reported using no tension 
Table 1: Respondent demographics (Total N=1083)

Please describe your gender.

Male

Female

Other

Prefer not to answer

Please choose your profession.

Physical Therapist

Chiropractor

Certified Athletic Trainer

Occupational Therapist

Acupuncturist

Physical Therapist Assistant

Occupational Therapist Assistant

Massage Therapist

Certified Personal Trainer

Kinesiotherapist

Exercise Physiologist

Educator (secondary schools, collegiate)

Physician Assistant

Medical Doctor, Podiatrist, Doctor of Osteopathy

Other profession not listed

Please choose your primary practice setting.

Private outpatient facility

Public outpatient facility (e.g. state, county)

Hospital based facility

University/college sports medicine or athletic training facility

Secondary school athletic training facility

Academic/research institution

Fitness or wellness facility

Massage therapy facility

Military service facility

In-home services

Professional sports

Skilled nursing facility/acute facility

Industrial/occupational health services

Other setting not listed

How many years have you been in professional practice?

Average years in professional practice
Frequency \% (N)

$45.43 \%$ (492)

$53.92 \%(584)$

$0.18 \%(002)$

$0.47 \%(005)$

$60.66 \%(657)$

$01.75 \%(19)$

$30.00 \%(325)$

$0.28 \%(3)$

$0.00 \%(0)$

$4.09 \%(44)$

$0.09 \%(1)$

$0.92 \%(10)$

$0.28 \%(3)$

$0.09 \%(1)$

$0.18 \%(2)$

$0.28 \%(3)$

$0.18 \%(2)$

$0.28 \%(3)$

$0.92 \%(10)$

$42.10 \%(456)$

$1.48 \%(16)$

$18.19 \%(197)$

$12.09 \%(131)$

$11.54 \%(125)$

$2.22 \%(24)$

$1.01 \%(11)$

$0.28 \%(3)$

$1.48 \%(16)$

$1.57 \%(17)$

$2.59 \%(28)$

$0.74 \%(8)$

$1.94 \%(21)$

$2.77 \%(30)$ length (Table 3).

Almost all the respondents indicated the commercially manufactured infused tapes $(99.54 \%, \mathrm{n}=1078)$ were not used in their clinical practice (Table 4). Similarly, most respondents $(65 \%, \mathrm{n}=704)$ also indicated not using any topical analgesic in combination with a non-infused KT. The most commonly utilized topical analgesics, however, were Biofreeze ${ }^{\circledR}(23 \%, n=255)$, RockTape RockSauce ${ }^{\circledR}$ Fire $(9 \%$, $\mathrm{n}=98)$, RockTape RockSauce ${ }^{\circledR}$ Ice $(7 \%, \mathrm{n}=77)$, Flexall ${ }^{\circledR}(6 \%$, $\mathrm{n}=61)$, and Voltaren ${ }^{\circledR}$ gel $(5 \%, \mathrm{n}=55)$ with non-infused $\mathrm{KT}$ (Table 4).
The most common clinical measures used by respondents to assess the efficacy of KT were patient reported outcomes (80\%, $\mathrm{n}=862)$, girth measurements (43\%, $\mathrm{n}=463)$, joint range of motion (40\%, $\mathrm{n}=435)$, sports specific assessment (40\%, $n=437)$, movement-based testing (36\%, $n=393$ ) and muscle performance (strength) testing $(31 \%, n=337)$ (Table 4).

\section{KT EDUCATION AND REFERRAL}

Regarding skin prep before applying KT, sixty-four percent $(n=695)$ of respondents provided client instructions. Com- 
Table 2: Clinical perceptions about KT $(\mathrm{N}=1083)$

*What are common reasons you use KT on your clients?

Performance enhancement

$20.78 \%(225)$

Injury prevention

$15.42 \%(167)$

Post-injury treatment (e.g. edema, ecchymosis)

$74.24 \%(804)$

Pain modulation

$66.85 \%(724)$

Neuro-sensory feedback (e.g. proprioception)

$60.30 \%(653)$

Myofascial mobility

$24.01 \%(260)$

Neuromuscular re-education

$45.52 \%(493)$

Pre-exercise warm-up

$1.39 \%(15)$

Post-exercise treatment

$6.00 \%(65)$

Placebo effect

$40.44 \%(438)$

Posture feedback

$0.64 \%(7)$

Patient requests $\mathrm{KT}$

Joint support

$0.46 \%(5)$

Edema or swelling

$0.74 \%(8)$

Other

$7.01 \%(76)$

*Which factors have influenced how you apply KT to your clients?

Peer reviewed research articles, textbooks

$53.55 \%(580)$

Continuing education courses or conferences

$74.33 \%(805)$

Manufacturer instructions

$28.90 \%(313)$

$\mathrm{KT}$ textbooks

$0.83 \%(9)$

Websites, social media posts, or videos (e.g. YouTube)

$31.10 \%(338)$

Collaboration with other professionals

$74.98 \%(812)$

My prior empirical experience

$64.08 \%(694)$

Patient interest

$1.66 \%(18)$

Other variables not listed

*What therapeutic effects do you believe occur with KT?

Enhanced myofascial mobility

$29.46 \%(319)$

Pain modulation

$69.80 \%(756)$

Increased joint ROM

$15.05 \%(163)$

Enhanced stretch tolerance of muscles

$13.48 \%(146)$

Enhanced post-exercise recovery

$12.56 \%(136)$

Enhanced pre-exercise neuromyofascial excitation

$13.11 \%(142)$

Enhanced proprioception and kinesthetic sense

$69.10 \%(748)$

Enhance muscle activation/motor control

$0.64 \%(7)$

Inhibit muscle activation/motor control

$0.28 \%(3)$

Increases in local circulation (e.g. lymphatic)

$65.47 \%(709)$

Decreased edema, swelling, and/or effusion

$0.28 \%(3)$

Postural awareness

$0.18 \%(2)$

Placebo effect

$58.63 \%(635)$

Other effects not listed

$3.23 \%(35)$

*Which physiological mechanisms do you believe occur with KT?

Tape lifts the skin to allow improved local circulation

$69.16 \%(749)$

Tape stimulates skin mechanoreceptors increasing proprioception

$77.00 \%(834)$

Tape stimulates skin nociceptors resulting in pain modulation

$60.20 \%(652)$

Tape help improve joint range of motion

$15.24 \%(165)$

Tape helps improve muscle performance (strength)

$13.85 \%(150)$

Tape helps improve muscle activation and motor control

$46.26 \%(501)$ 
Tape can inhibit muscle activation

$31.86 \%(345)$

Tape can create a placebo effect

$73.68 \%(798)$

Other physiological mechanisms not listed

$1.38 \%(15)$

*What therapeutic effects do you believe occur with your preferred KT tension length you use with clients?

Enhanced myofascial mobility

$23.45 \%(254)$

Pain modulation

Increased joint ROM

$9.42 \%(102)$

Enhanced stretch tolerance of muscles

$10.80 \%(117)$

Enhanced post-exercise recovery

$6.74 \%(73)$

Enhanced pre-exercise neuromyofascial excitation

$10.06 \%(109)$

Enhanced proprioception and kinesthetic sense

$58.73 \%(636)$

Increases in local circulation (e.g. lymphatic)

$43.31 \%(469)$

Placebo effect

Joint stability

$0.83 \%(9)$

Muscle inhibition

$0.18 \%(2)$

Other effects not listed

$1.01 \%(11)$

**Which general precautions do you believe are most important with kinesiology tape?

Skin reaction/allergy (e.g. irritation, itching)

$50.69 \%(549)$

Thin skin (e.g. common in elderly)

$25.48 \%(276)$

Lymph node removal

$2.86 \%(31)$

Connective tissue disorder (e.g. Marfan syndrome)

$3.79 \%(41)$

Medications that alter sensation

$1.57 \%(17)$

Pregnancy

$1.39 \%(15)$

impaired or altered sensation

$9.08 \%(87)$

Unusual pain or discomfort

$6.19 \%(67)$

${ }^{* * *}$ What other precautions should professionals consider with kinesiology tape?

No other precautions

$94.92 \%(1,028)$

Prior skin reaction to $\mathrm{KT}$

$0.74 \%(8)$

Allergy to adhesives or latex

$0.74 \%(8)$

Patient understanding, compliance, and self-efficacy

$1.01 \%(11)$

Patient ability to self-apply tape

$0.37 \%(4)$

Patients with impaired judgement/cognition

$0.65 \%(7)$

Other reason not listed above

$1.57 \%(17)$

${ }^{* *}$ Which contraindications do you believe are most important with kinesiology tape?

Diabetes

$2.40 \%(26)$

Peripheral neuropathy

$1.39 \%(15)$

Acute injury

$1.57 \%(17)$

Skin with open wounds or lesions

$32.87 \%(356)$

Allergy to adhesives, latex, or synthetic tapes

$33.33 \%(361)$

Deep vein thrombosis

$4.80 \%(52)$

Congestive heart failure

$1.66 \%(18)$

Malignancy (active)

$3.51 \%(38)$

Renal insufficiency

$0.28 \%(3)$

Infection or fever

$1.85 \%(20)$

Undiagnosed rash or skin irritation

$3.69 \%(40)$

Inability to communicate

$13.48 \%(146)$

Lymph edema

$0.55 \%(6)$

${ }^{* *}$ What other contraindications should professionals consider with kinesiology tape? 
mon instructions included to clean and dry skin (53\%, $\mathrm{n}=576)$, avoid lotions, oils, topicals, or gels $(37 \%, \mathrm{n}=396)$, and trim or remove hair on the body region $(12 \%, n=131)$ being taped. Thirty-six percent $(n=388)$ of respondents did not provide any skin prep instruction (Table 5).

Most respondents $(77 \%, \mathrm{n}=837)$ provided tape removal instructions to the clients. Common instructions included slowly removing tape $(44 \%, \mathrm{n}=474)$, applying oil (mineral, baby) to tape or use of adhesive remover $(18 \%, n=191)$, wetting tape before removal $(10 \%, n=113)$, and do not rip off tape $(7 \%, n=67)$. Twenty-three percent $(n=246)$ did not provide any tape removal instructions (Table 5).

The average time respondents recommended clients to wear KT was two $(32 \%, n=344)$ and three days $(38 \%, n=406)$. The maximum time respondents recommended clients to wear KT was for five days $(33 \%, n=357)$, three days $(24 \%$, $\mathrm{n}=259)$, four days $(13 \%, \mathrm{n}=140)$, and two days $(11 \%, \mathrm{n}=114)$ (Table 5).

The most common type of client education was live instruction (89\%, $n=960)$, and most respondents referred clients to generic websites $(65 \%, \mathrm{n}=704)$, retail stores $(43 \%$, $\mathrm{n}=469)$, or manufacturer websites $(26 \%, \mathrm{n}=277)$ to purchase KT. Twenty four percent $(n=258)$ of respondents did not provide recommendations to clients on KT purchases (Table 5).

\section{DISCUSSION}

This cross-sectional study was the first survey to document healthcare professionals' beliefs and clinical practices for KT. We attempted to provide insight into the practices of clinicians using KT and to answer clinical questions that have been unanswered in the body of KT evidence to inform future research. The results of our study, combined with the immense body of research, may help discern why inconsistencies may be found in the literature, while also providing awareness of common clinical KT practices to guide future research efforts.

\section{RESPONDENT CLINICAL PERCEPTIONS OF KT}

Professionals reported using KT for pain modulation (60-70\%) , neuro-sensory feedback (e.g. proprioception) (60-77\%), neuromuscular re-education (45-46\%), post-injury treatment (e.g. increase local circulation; 65-74\%), myofascial mobility (24-29\%), and placebo effect (40-74\%). The respondents, however, reported using continuing education (74\%), professional collaboration (75\%), and prior experience (64\%) to inform their clinical application of KT with clients. Interestingly, these sources were noted more often than peer reviewed research (53\%). The current results are similar to prior myofascial intervention survey research examining clinician perceptions of IASTM; clinicians often sought out informal sources of information and utilize personal experience to guide their clinical practice. ${ }^{44}$ The varied sources of information and training may also help explain the variations in KT use in clinical practice and research, while also potentially explaining respondent beliefs about the clinical use, therapeutic benefits, and physiological effects of KT. Thus, clinician beliefs may be influenced by peer-reviewed research; however, it is also possible clinician beliefs may be more influenced by informal educational sources, as part of KT training provided by a commercial entity, or by their own clinical experiences than by the research evidence (Table 2).

For pain modulation, the research is inconclusive with some studies reporting poor efficacy when using KT for pain related to musculoskeletal injury ${ }^{2}$ and chronic musculoskeletal pain. ${ }^{16,17}$ While some researchers report weak to moderate evidence for myofascial ${ }^{30}$ and low back pain. ${ }^{32-34}$ For post-exercise soreness, several researchers have documented that KT may diminish the effects of delayed onset of muscle soreness (DOMS) after intense exercise. ${ }^{45-48}$ For neuro-sensory feedback and muscle re-education, there are mixed results in the literature. Two studies compared KT versus placebo on knee joint position sense in healthy subjects; ${ }^{49,50}$ a significant group differences was not found in either study, questioning the efficacy of KT for this type of intervention. Other researchers, however, have reported KT improved proprioception in post-ACL repair individuals ${ }^{51}$ and elderly individuals when the tape was combined with exercise (Table 2). ${ }^{52}$

For increasing circulation post injury/surgery, several studies suggest KT may increase local microcirculation ${ }^{53-55}$ and skin temperature, ${ }^{53-55}$ while decreasing tissue edema. ${ }^{56}$ Other researchers, however, did not find any significant changes in local microcirculation after KT was applied. ${ }^{57}$ Respondents also use KT to enhance myofascial mobility, which has some evidence in the literature for causing deformation of the different skin and myofascial layers locally 58,59 and distally ${ }^{59}$ which supports the mechanical effects of the tape.

A substantial portion of respondents also believed KT only creates a physiological placebo (40\%), and a large portion of respondents indicated using it for such therapeutic placebo effects (58\%) with their clients (Table 2). Several studies have investigated the placebo effects of facilitatory and inhibitory KT taping techniques. One study found that KT promoted increased grip strength among healthy individuals but did not find any electromyography (EMG) 
Table 3: Clinical application of standard and specialty KT $(\mathrm{N}=1083)$

*Which commercial brand KT do you commonly use in your practice?

KT Tape

$59.10 \%(640)$

RockTape

$50.41 \%(546)$

Kinesio Tex

$33.15 \%$ (359)

P-Tex

$0.37 \%(4)$

TheraBand

$10.71 \%$ (116)

Spider Tech

$3.42 \%$ (37)

Strength Tape

$1.02 \%(11)$

Mueller

$7.39 \%(80)$

Dynamic

$3.41 \%$ (37)

Levotape

$0.83 \%(9)$

Leukotape

$0.18 \%(2)$

Other brands not listed

$9.04 \%(98)$

${ }^{*}$ Which color/s of KT do you use most often with your clients? (colors without specialty designs)

Black

$71.47 \%(774)$

Beige

$65.83 \%(713)$

Blue

$30.66 \%(332)$

Pink

$17.63 \%(191)$

Green

$2.68 \%(29)$

Purple

$4.80 \%(52)$

Red

$7.94 \%(86)$

Yellow

$0.46 \%(5)$

Orange

$0.37 \%(4)$

Skin tone

$0.46 \%(5)$

White

$0.27 \%(3)$

*Which types of standard KT do you use most often on your clients? (standard roll and pre-cut tape)

Pre-cut strips (2 in $\times 10$ in) $(5 \mathrm{~cm} \times 25 \mathrm{~cm}$ )

$15.51 \%(168)$

Pre-cut strips ( 4 in $\times 10 \mathrm{in})(10 \mathrm{~cm} \times 25 \mathrm{~cm})$

$3.05 \%(33)$

Pre-cut strips for digits ( $1 \mathrm{in} \times 10 \mathrm{in})(2.54 \mathrm{~cm} \times 25 \mathrm{~cm})$

$0.37 \%(4)$

Uncut roll $(2$ in $\times 16.4 \mathrm{ft})(5 \mathrm{~cm} \times 5 \mathrm{~m})$

$66.85 \%(724)$

Uncut roll ( 3 in $\times 16.4 \mathrm{ft})(7.5 \mathrm{~cm} \times 5 \mathrm{~m})$

$10.53 \%(114)$

Uncut roll (4 in $\times 16.4 \mathrm{ft})(10 \mathrm{~cm} \times 5 \mathrm{~m})$

$6.19 \%(67)$

Uncut roll for digits ( 1 in $\times 16.4 \mathrm{ft})(2.5 \mathrm{~cm} \times 5 \mathrm{~m})$

$0.74 \%(8)$

Uncut large roll (2 in $\times 105 \mathrm{ft})(5 \mathrm{~cm} \times 32 \mathrm{~m})$

$35.92 \%$ (389)

Uncut large roll (4 in $\times 105 \mathrm{ft})(10 \mathrm{~cm} \times 32 \mathrm{~m})$

$4.71 \%(51)$

*Which types of specialty pre-cut KT do you most often use in your practice?

Blister prevention tape

$0.92 \%(10)$

Pre-cut fan tape (e.g. edema, bruising, lymphatic drainage)

$8.86 \%(96)$

Pre-cut X tape

$2.03 \%(22)$

Pre-cut tape for the upper body regions

$3.51 \%(38)$

Pre-cut tape for the lower body regions

$3.97 \%(43)$

I do not use specialty pre-cut tape

$83.28 \%(902)$

I cut my own tape

$0.37 \%(4)$

When applying the $\mathrm{KT}$, what is the most common tension length percentage you use for your clients?

$25 \%$ tension

$24.75 \%(268)$

$50 \%$ tension

$47.09 \%(510)$

$75 \%$ tension

$18.37 \%(199)$

$100 \%$ tension

$2.12 \%(23)$ 


$\begin{array}{lr}125 \% \text { tension } & 0.74 \%(8) \\ 150 \% \text { tension } & 0.28 \%(3) \\ 175 \% \text { tension } & 0.09 \%(1) \\ \text { No tension } & 6.56 \%(71)\end{array}$

* Respondents chose all options that applied to them; KT= kinesiology tape

changes in the forearm muscles, which suggests some type of indirect placebo effect. ${ }^{60}$ Others have not found any differences between KT facilitation, inhibition, sham taping, or no taping for muscle activity, strength, power, or perceived maximum strength for the forearm muscles, ${ }^{61-63}$ quadriceps, ${ }^{64-67}$ and calf muscles. ${ }^{67}$ Researchers have also reported no therapeutic differences between KT, sham tape, and control group for individuals with lateral epicondylitis ${ }^{68-70}$ and chronic low back pain. ${ }^{71}$ Professionals should consider that these results are limited to the study methods (e.g. placebo) and study populations; further research is needed to confirm or refute the placebo effects for different populations.

For KT tension length, most of the respondents believed their preferred tape tension length enhanced proprioception and kinesthetic sense (59\%) and modulated pain (55\%), while a substantial portion felt it increased local circulation (43\%), enhanced myofascial mobility (23\%)., and provided a placebo effect (40\%) (Table 2). The research on the efficacy of tape length tension will be further discussed in the next section on clinical application of KT.

For precautions, most respondents considered skin reaction (51\%), thin skin (25\%), and impaired or altered sensation (e.g. diabetes neuropathy) as the most important to consider for potential KT application adverse events (Table 2). There is a small body of research that has directly studied the side effects and tolerability of KT among individuals with neurological disorders, ${ }^{72,73}$ cancer related lymphoedema, ${ }^{74,75}$ and healthy individuals. ${ }^{76}$ The incidences of side effects (e.g. skin reaction) or intolerance reported among these studies ranged between $4 \%$ to $33 \% .{ }^{72-77} \mathrm{Un}$ fortunately, the research on KT side effects is sparse. The existing data may not represent the actual number of occurrences among different client populations such as athletes and individuals with musculoskeletal disorders. ${ }^{77}$ These two populations may use KT the most and may not be well represented in the current literature. Sports medicine professionals could benefit from knowing the incident rates of KT side effects in this population to improve clinical decision making and inform their practice patterns.

For KT contraindications, most respondents considered skin allergies (33\%), open wounds and lesions (33\%), and inability to communicate $(13 \%)$ as the most important (Table 2). Some researchers suggest using a small piece of KT on the forearm to check for a skin reaction to the tape (e.g. redness, itching, etc) noted within 15 minutes. ${ }^{78}$ These precautions and contraindication align with recommendations in the literature but may not represent all possible conditions. ${ }^{77,79-81}$ Professionals should consider that these conditions have not been fully investigated and should properly screen each client prior to administering KT as an intervention.

\section{CLINICAL APPLICATION OF KT}

Most respondents (47\%) purchased tape from three manufacturers, but our results also indicate that clinicians utilize KT from a variety of manufacturers. Clinicians reported using a variety of popular KT colors with clients: black (71\%), beige (66\%), blue (31\%), and pink (18\%) (Table 3). Researchers have previously examined the influence of KT color on athletic performance, quadriceps strength, and neuromuscular function among healthy individuals. ${ }^{82}$ Five conditions were measured: no tape, KT beige sham, beige KT with $50 \%$ tension, red KT with $50 \%$ tension, and blue KT with $50 \%$ tension. ${ }^{82}$ The researchers found that KT, regardless of color or condition, did not alter athletic performance, lower leg strength, or neuromuscular function. ${ }^{82}$ The current evidence suggests clinicians may utilize the KT colors preferred by their clients without concerns for it detrimentally affecting athletic performance.

Respondents most often used the KT standard uncut rolls (67\%), followed by the large standard uncut roll (36\%) then standard pre-cut strips (15\%). These respondents did not indicate the use of any specialty pre-cut strips (83\%), commercially infused tape (99\%), or a combination of a topical analgesic and non-infused tape (65\%) in clinical practice; however, a small portion of respondents (23\%) did report combining Biofreeze with non-infused tape (Table $\underline{3}$ and 4 ). While previous research on KT practice patterns was not identified in the literature, the current findings are not unexpected. Clinicians have reported using a variety of IASTM instruments and utilizing instruments from numerous manufactures ${ }^{44}$; thus, it is not surprising to have similar practice patterns arise with KT. Research regarding the therapeutic effects of different infused KT or the effects of a non-infused KT with a topical analgesic was also not identified in the literature. Due to this lack of evidence, professionals will need to rely on the assessment of patient outcomes and good clinical judgement when matching a specific tape to their clients.

Respondents reported commonly used a KT tension length range of $25-75 \%$, with $50 \%$ tension (47\%) being the most used among respondents (Table 3). While the actual tension force being used was not validated with the survey responses and the current results do not elucidate whether or how clinicians adjust the tension length based on pathology or patient need; however, the respondent choices for tension length are consistent with general KT recommendations in the literature. A $25 \%$ to $50 \%$ tape tension length has been recommended for treatment of fascia and circulatory conditions, stimulating, and inhibiting muscle activity. ${ }^{83}$ A tension length range of 75 to $100 \%$ has been recommended for treatment of tendons and ligaments. ${ }^{83}$ These recommendations are often shared among profes- 
Table 4: Clinical application of Infused KT, topicals, and clinical measures $(\mathrm{N}=1083)$

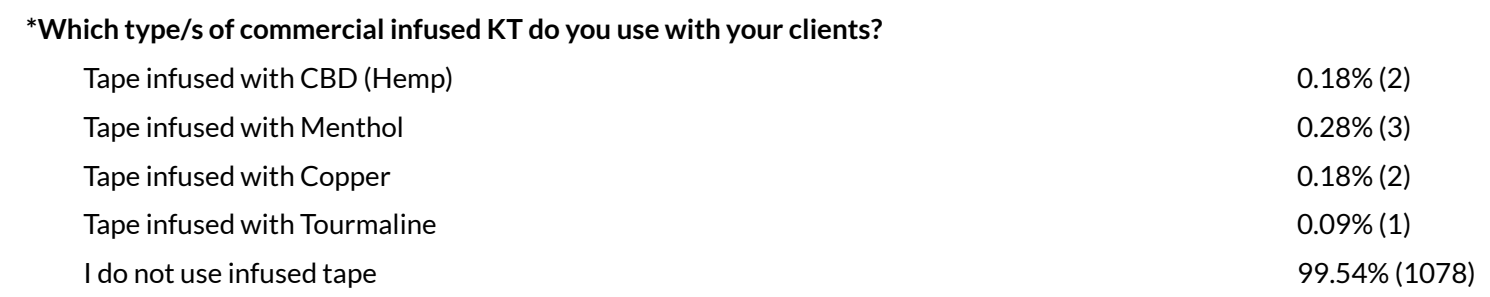

*Which commercially available topical analgesic/s due you use in combination with non-infused KT? (most common brands or types)

\begin{tabular}{|c|c|}
\hline Biofreeze & $23.55 \%(255)$ \\
\hline Tiger Balm & $3.51 \%(38)$ \\
\hline Flexall & $5.63 \%(61)$ \\
\hline RockSauce Fire & $9.05 \%(98)$ \\
\hline RockSauce Ice & $7.11 \%(77)$ \\
\hline Solonpas & $1.29 \%(14)$ \\
\hline IcyHot & $1.39 \%(15)$ \\
\hline Mineral Ice & $0.18 \%(2)$ \\
\hline Ben Gay & $0.18 \%(2)$ \\
\hline CBD Topical & $2.22 \%(24)$ \\
\hline Cramer Atomic Balm & $1.75 \%(19)$ \\
\hline Arnica & $3.60 \%(39)$ \\
\hline Voltaren Gel & $5.08 \%(55)$ \\
\hline Hydro cortisone & $0.92 \%(10)$ \\
\hline Sombra & $1.75 \%(19)$ \\
\hline Other brands not listed & $3.51 \%(38)$ \\
\hline I do not use any topical analgesic & $65.00 \%(704)$ \\
\hline \multicolumn{2}{|l|}{ hat clinical measures do you use to assess the effects of KT? } \\
\hline Joint range of motion (e.g. goniometer, inclinometer) & $40.17 \%(435)$ \\
\hline Pressure pain threshold (e.g. algometer) & $17.08 \%(185)$ \\
\hline Patient reported outcomes (e.g. NRS, VAS pain scales) & $79.59 \%(862)$ \\
\hline Movement based testing (e.g. FMS, SFMA) & $36.29 \%(393)$ \\
\hline Muscle performance (strength) testing & $31.12 \%(337)$ \\
\hline Activity or sports specific assessment & $40.35 \%(437)$ \\
\hline Girth measurements (e.g. edema) & $42.75 \%(463)$ \\
\hline Gait assessment & $0.55 \%(6)$ \\
\hline Palpation & $0.37 \%(4)$ \\
\hline Observation/visual changes & $0.65 \%(7)$ \\
\hline Other measures not listed & $0.92 \%(10)$ \\
\hline I do not use clinical measures to assess the effects of KT & $11.08 \%(120)$ \\
\hline
\end{tabular}

* Respondents chose all options that applied to them; KT= kinesiology tape; CBD: Cannabidiol

sionals, but are not necessarily evidence based.

Different KT tensions were not found to have positive effects among healthy individuals for quadriceps strength, ${ }^{84,85}$ knee joint range of motion, ${ }^{85}$ lower extremity hop test, ${ }^{84}$ the gastrocnemius and soleus H-Reflex, ${ }^{86,87}$ and EMG activity of the quadriceps and hamstrings during a loaded squat exercise. ${ }^{88}$ However, other researchers have reported that KT does facilitate the H-Reflex ${ }^{89}$ and shoulder muscle EMG activity ${ }^{90}$ among healthy individuals. Researchers have also documented that different tape tension lengths (15-50\%) did not produce significant changes in EMG paraspinal muscle activity among individuals with chronic low back pain ${ }^{91,92}$ and non-specific low back pain. ${ }^{93}$ The research on KT tension length is inconclusive and has been focused more on healthy versus injured participants, which presents a barrier for interpreting the research. Without sound evidence to guide practice, professional will be forced to rely on their clinical outcomes, personal preferences, or information from informal sources to guide tension length due to the lack of evidence. 
Table 5: KT education and referral $(\mathrm{N}=1083)$

Do you instruct your clients to prepare their skin before applying the KT?

Yes

$64.17 \%(695)$

No

*If yes to the prior question, what instructions do you provide to your clients?

Clean and dry skin (e.g. soap/water, isopropyl alcohol)

$53.18 \%(576)$

Avoid lotions, oils, topicals, or gels

$36.56 \%(396)$

Trim or remove hair in body region

$12.10 \%(131)$

Inspect skin integrity, rashes, open wounds, etc.

$1.10 \%(12)$

Do you instruct your clients on how to safely remove the KT?

Yes

$77.29 \%(837)$

No

$22.71 \%(246)$

*If yes, what instructions do you provide to your clients for removing KT?

Wet tape before removal

$10.44 \%(113)$

Remove tape slowly

$43.77 \%(474)$

Remove tape slowly and pull skin in opposite direction

$1.75 \%(19)$

Remove tape in the direction of hair growth

$5.35 \%(58)$

Remove tape parallel to skin

$2.21 \%(24)$

Apply oil (baby, mineral) to tape, or use adhesive remover

$17.64 \%(191)$

Do not rip off tape

$6.19 \%(67)$

What is the average time you recommend clients to wear KT?

Less than One Day

$2.40 \%(26)$

One Day

$8.59 \%(93)$

Two Days

$31.76 \%(344)$

Three Days

$37.49 \%(406)$

Four Days

$8.03 \%(87)$

Five Days

$4.06 \%(44)$

Greater than 5 days

$1.57 \%(17)$

I do not recommend

$6.09 \%(66)$

What is the maximum time you recommend clients to wear the KT?

Less than One Day

$1.11 \%(12)$

One Day

$3.14 \%(34)$

Two Days

$10.53 \%(114)$

Three Days

$23.92 \%(259)$

Four Days

$12.93 \%(140)$

Five Days

$32.96 \%(357)$

Greater than 5 days

$5.82 \%(63)$

I do not recommend

$9.60 \%(104)$

${ }^{* *}$ What are common types of education you use to teach clients about KT?

Live instruction

$88.64 \%(960)$

Video instruction

Self-guided program (e.g. client chooses parameters)

$3.97 \%(43)$

Education materials (e.g. handouts with exercises)

***Where do you direct your clients to purchase KT?

Manufacturer website

Generic websites (e.g. Amazon)

Retail Store (brick and mortar)

Sell in my facility

$16.90 \%(183)$

Provide it free to patients 
* Respondents provided answers in a comment section; **Respondents ranked their answers; ***Respondents chose all options that applied to them

For clinical measures, most respondent used patient reported outcomes (80\%), girth measurement (43\%), joint ROM (40\%), movement-based testing sports specific assessments (40\%), movement-based testing (36\%), and muscle performance (31\%) to measure the effects of KT (Table 4$)$. These outcomes are commonly used in the research $^{2,18,27-30,33}$ and are similar to the types of outcome measures used by clinicians when assessing the effectiveness of IASTM. ${ }^{44}$

\section{KT EDUCATION AND REFERRAL}

For skin prep, most respondents (64\%) instructed patients to clean and dry skin first, avoid topical lotions, oils, and gels, and to trim or remove hair on the body region being taped. For KT removal, most respondents (77\%) instructed their patients to slowly remove the tape, applying oil (mineral, baby) to tape or use of adhesive remover, wet tape before removal, and do not rip off the tape (Table 5$)$. The results of the survey demonstrate some common instructions often taught by tape manufacturers or shared among professionals. ${ }^{77}$ The most concerning finding was that $36 \%$ of respondents did not provide any skin prep instructions and $23 \%$ did not provide any tape removal instructions to their clients (Table 5). The current findings are consistent with previous research on IASTM clinician practice patterns for following training recommendations; researchers reported that more than $45 \%$ of their respondents indicated failing to following training recommendations from some to all the time. ${ }^{44}$ The lack of instruction or failure to following training or best practice recommendations may present a risk for injury because the clinician or client may not use the tape correctly. Currently, research is lacking on the best practice recommendations for skin prep and KT removal and little is known about any potential related complications (e.g. allergic reaction, infection, etc.) to KT use in this area.

For length of time wearing tape, most respondents (70\%) recommended for clients to wear KT an average of two to three days with a maximum wear time of three to five days (Table 5). These recommendation are consistent with research that has examined the effects of KT wear time of three to seven days on balance and functional performance among healthy individuals, ${ }^{94}$ among individuals with myofascial pain syndrome and trigger points, ${ }^{95-98}$ chronic ankle instability, ${ }^{99}$ subacromial shoulder impingement, ${ }^{100,101}$ rheumatoid arthritis, ${ }^{102}$ knee osteoarthritis, ${ }^{103}$ total knee replacement, ${ }^{104}$ and lymphedema. ${ }^{105}$ Studies have also been performed measuring hamstring extensibility, ${ }^{106}$ increased local tissue temperature, ${ }^{54}$ and quadriceps strength ${ }^{107}$ in subjects wearing KT within this time range. Survey respondent recommendations for KT wear time seem to be in line with the research. Professionals should determine KT wear time on an individual basis and always monitor for side effects such as skin irritation or allergy, ${ }^{77}$ and future research should examine how clinicians adjust wear time based on client need or clinical scenario.

Most respondents used live education (89\%) for the clients and referred them to generic websites (65\%) and retails stores (43\%) to purchase KT. Twenty four percent did not provide recommendations (Table 5). Unfortunately, there is no research measuring the efficacy of different modes or instruction or the influences on professional referral to purchase KT. Only one related myofascial intervention study measured the efficacy of different modes of education for myofascial rolling. The researchers compared a 2-minutes live instruction, video instruction, and a selfadministered program for the quadriceps. The study outcomes were passive knee flexion range of motion and pain threshold. The researchers found that all modes produced similar post intervention outcomes for all measures. The researchers concluded that professionals should match the best instructional mode to each patient to provide the best experience. ${ }^{108}$ Future studies are needed with KT.

\section{PRACTICE IMPLICATIONS AND FUTURE RESEARCH}

This survey revealed several trends in the beliefs and clinical application of KT among healthcare professionals: a gap exists between the respondent beliefs, professional practices, and the current evidence. Weaknesses in the research for guiding clinical practice may be caused by two primary issues: tape manufacturing and study method differences. First, the large body of research consists of studies that have used different tape brands. This presents a major issue when comparing study outcomes due to the differences among tape mechanical properties (e.g. tension, strain). Three recent studies measured the material and mechanical properties of 23 different KT brands and found all had different mechanical properties making it difficult for a direct comparison across studies. ${ }^{83,109,110}$ Second, most of the KT research has variable outcomes due to different study methods and these study methods do not always match common clinical practice. Researchers have used different manufactured tape, taping techniques (e.g. tape elongation length), and outcomes which prevents a direct comparison or reproducibility among studies or direct translation to clinical practice. ${ }^{11,12,18}$

The KT conflicting evidence creates a gap between professional practice, education, and research. Professionals may rely on their own preferred KT techniques because there are discrepancies between the KT guidelines, techniques taught in professional education courses, ${ }^{77}$ application in clinical practice, and what is reported in the research. As noted in the introduction, thirty-eight systematic reviews have been published since 2010 with inconclusive results. These issues may reflect the portion of 
respondents that believe KT only creates a physiological placebo (40\%) and use it for such therapeutic placebo effects (59\%) with their clients. Future research needs to address the issues of variations across tape manufacturing and study methods, while also exploring adverse and long-term effects of KT application. Further, researchers need to establish the most common clinical practice patterns for KT application to inform study methodologies. In addition to examining the effects of KT, researchers also must learn how clinician training influences KT application and patient outcomes, how clinicians determine KT tension and wear time and how these factors influence patient outcomes, and how individual client differences (e.g., age, activity level, pathology, etc.) influence KT application.

\section{LIMITATIONS}

Several limitations need to be discussed for this investigation. First, this survey was sent electronically to a crosssectional sample of healthcare professionals with a $2.1 \%$ response rate. A larger sample or a different method for sampling with a higher response rate may have produced different results; the results could be influenced by non-response error. However, to the researcher's knowledge this is the first KT survey study. Second, the results can only be generalized to the healthcare professionals surveyed. Other healthcare professionals may have provided different responses. Third, the survey contained a limited number of items. Different questions may have revealed different ideas of how professionals use KT. For example, the survey did not ask about respondent preference for KT direction such as the tape is tensioned along muscle origin to insertion for facilitation or opposite for inhibition. The current evidence contradicts these directional techniques. ${ }^{111-114}$ The survey focused on tape tension length only versus direc- tional strategies. Finally, this survey was sent to members of three professional organizations. The results many not fully represent the perceptions and practices from other non-member healthcare professionals. However, the results do provide insight into responses among different healthcare professionals, but further research is needed to determine how respondent demographics may have influenced KT perceptions.

\section{CONCLUSION}

This is the first KT survey to document professional beliefs and clinical practices for KT. Professionals use different types and brands of KT. They also apply KT with different lengths and tensions to treat a variety of conditions, including as a placebo by nearly $60 \%$ of the respondents. Professionals also believe KT provides numerous positive therapeutic effects for clients, but little is known regarding how the therapeutic effects might be produced with KT application. The KT conflicting results may be caused by two primary issues: tape manufacturing and study method differences. Future research addressing these two issues should be pursued to validate or refute the efficacy of KT.

\section{CONFLICT OF INTEREST STATEMENT}

The authors have no conflicts of interest with this study.

Submitted: September 01, 2020 CDT, Accepted: November 26, 2020 CDT 


\section{REFERENCES}

1. Drouin JL, McAlpine CT, Primak KA, et al. The effects of kinesiotape on athletic-based performance outcomes in healthy, active individuals: A literature synthesis. J Can Chiropr Assoc. 2013;57(4):356-365.

2. Montalvo AM, Cara EL, Myer GD. Effect of kinesiology taping on pain in individuals with musculoskeletal injuries: Systematic review and meta-analysis. Phys Sportsmed. 2014;42(2):48-57. do i:10.3810/psm.2014.05.2057

3. Celik D, Karaborklu Argut S, Coban O, Eren I. The clinical efficacy of kinesio taping in shoulder disorders: A systematic review and meta analysis. Clin Rehabil. 2020;34(6):723-740. doi:10.1177/0269215520 $\underline{917747}$

4. Ghozy S, Dung NM, Morra ME, et al. Efficacy of kinesio taping in treatment of shoulder pain and disability: A systematic review and meta-analysis of randomised controlled trials. Physiotherapy. 2020;107:176-188. doi:10.1016/j.physio.2019.12.001

5. Ye W, Jia C, Jiang J, Liang Q, He C. Effectiveness of Elastic Taping in Patients With Knee Osteoarthritis: A Systematic Review and Meta-Analysis. Am J Phys Med Rehabil. 2020;99(6):495-503. doi:10.1097/phm.00000 $\underline{00000001361}$

6. George CE, Heales LJ, Stanton R, Wintour S-A, Kean CO. Sticking to the facts: A systematic review of the effects of therapeutic tape in lateral epicondylalgia. Phys Ther Sport. 2019;40:117-127. do i:10.1016/j.ptsp.2019.08.011

7. Vanti C, Bertozzi L, Gardenghi I, Turoni F, Guccione AA, Pillastrini P. Effect of taping on spinal pain and disability: Systematic review and meta-analysis of randomized trials. Phys Ther. 2015;95(4):493-506. do i:10.2522/ptj.20130619

8. Ager AL, Borms D, Bernaert M, et al. Can a Conservative Rehabilitation Strategy Improve Shoulder Proprioception? A Systematic Review. J Sport Rehabil. 2020;30(1):136-151. doi:10.1123/jsr.20 $\underline{19-0400}$

9. Hassan BS, Abbass ME, Elshennawy S. Systematic review of the effectiveness of Kinesio taping for children with brachial plexus injury. Physiother Res Int. 2020;25(1):e1794. doi:10.1002/pri.1794

10. Csapo R, Alegre LM. Effects of Kinesio ${ }^{\circledR}$ taping on skeletal muscle strength-A meta-analysis of current evidence. J Sci Med Sport. 2015;18(4):450-456. doi:1 0.1016/j.jsams.2014.06.014
11. Reneker JC, Latham L, McGlawn R, Reneker MR. Effectiveness of kinesiology tape on sports performance abilities in athletes: A systematic review. Phys Ther Sport. 2018;31:83-98. doi:10.1016/ j.ptsp.2017.10.001

12. Parreira P do CS, Costa L da CM, Hespanhol LC Jr, Lopes AD, Costa LOP. Current evidence does not support the use of Kinesio Taping in clinical practice: A systematic review. J Physiother. 2014;60(1):31-39. d oi:10.1016/i.jphys.2013.12.008

13. Kalron A, Bar-Sela S. A systematic review of the effectiveness of Kinesio Taping--fact or fashion? Eur J Phys Rehabil Med. 2013;49(5):699-709.

14. Morris D, Jones D, Ryan H, Ryan CG. The clinical effects of Kinesio ${ }^{\circledR}$ Tex taping: A systematic review. Physiother Theory Pract. 2013;29(4):259-270. doi:10.3 $\underline{109 / 09593985.2012 .731675}$

15. Mostafavifar M, Wertz J, Borchers J. A systematic review of the effectiveness of kinesio taping for musculoskeletal injury. Phys Sportsmed. 2012;40(4):33-40. doi:10.3810/psm.2012.11.1986

16. Lim ECW, Tay MGX. Kinesio taping in musculoskeletal pain and disability that lasts for more than 4 weeks: Is it time to peel off the tape and throw it out with the sweat? A systematic review with meta-analysis focused on pain and also methods of tape application. Br J Sports Med. 2015;49(24):1558-1566. doi:10.1136/bjsports-2014-09 $\underline{4151}$

17. Sheng Y, Duan Z, Qu Q, Chen W, Yu B. Kinesio taping in treatment of chronic non-specific low back pain: A systematic review and meta-analysis. $J$ Rehabil Med. 2019;51(10):734-740. doi:10.2340/16501 977-2605

18. Williams S, Whatman C, Hume PA, Sheerin K. Kinesio taping in treatment and prevention of sports injuries: A meta-analysis of the evidence for its effectiveness. Sports Med. 2012;42(2):153-164. doi:1 $\underline{0.2165 / 11594960-000000000-00000}$

19. Kasawara KT, Mapa JMR, Ferreira V, et al. Effects of Kinesio Taping on breast cancer-related lymphedema: A meta-analysis in clinical trials. Physiother Theory Pract. 2018;34(5):337-345. doi:10.1 $\underline{080 / 09593985.2017 .1419522}$

20. Ortiz Ramírez J, Pérez de la Cruz S. Therapeutic effects of kinesio taping in children with cerebral palsy: A systematic review. Arch Argent Pediatr. 2017;115(6):356-361. doi:10.5546/aap.2017.eng.e356 
21. Unger M, Carstens JP, Fernandes N, et al. The efficacy of kinesiology taping for improving gross motor function in children with cerebral palsy: A systematic review. S Afr J Physiother. 2018;74(1):459. doi:10.4102/sajp.v74i1.459

22. Cunha AB, Lima-Alvarez CD, Rocha ACP, Tudella E. Effects of elastic therapeutic taping on motor function in children with motor impairments: A systematic review. Disabil Rehabil.

2018;40(14):1609-1617. doi:10.1080/09638288.2017.1 $\underline{304581}$

23. Ravichandran H, Janakiraman B, Sundaram S, Fisseha B, Gebreyesus T, Yitayeh Gelaw A. Systematic review on effectiveness of shoulder taping in hemiplegia. J Stroke Cerebrovasc Dis. 2019;28(6):1463-1473. doi:10.1016/j.jstrokecerebrova sdis.2019.03.021

24. Wang M, Pei Z-W, Xiong B-D, Meng X-M, Chen XL, Liao W-J. Use of Kinesio taping in lower-extremity rehabilitation of post-stroke patients: A systematic review and meta-analysis. Complement Ther Clin Pract. 2019;35:22-32. doi:10.1016/j.ctcp.2019.01.008

25. Hu Y, Zhong D, Xiao Q, Chen Q, Li J, Jin R. Kinesio taping for balance function after stroke: A systematic review and meta-analysis. Evid Based Complement Alternat Med. 2019;2019:8470235. doi:10.1155/2019/8 $\underline{470235}$

26. Grampurohit N, Pradhan S, Kartin D. Efficacy of adhesive taping as an adjunt to physical rehabilitation to influence outcomes post-stroke: A systematic review. Top Stroke Rehabil. 2015;22(1):72-82. doi:10.1179/1074935714z.0000000 031

27. Wang Y, Gu Y, Chen J, et al. Kinesio taping is superior to other taping methods in ankle functional performance improvement: A systematic review and meta-analysis. Clin Rehabil. 2018;32(11):1472-1481. $\underline{\mathrm{d}}$ oi: $10.1177 / 0269215518780443$

28. Yam ML, Yang Z, Zee BC-Y, Chong KC. Effects of kinesio tape on lower limb muscle strength, hop test, and vertical jump performances: A meta-analysis. BMC Musculoskelet Disord. 2019;20(1):212. doi:10.118 6/s12891-019-2564-6

29. Lau KK-L, Cheng KC-C. Effectiveness of taping on functional performance in elite athletes: A systematic review. J Biomech. 2019;90:16-23. doi:10.1016/j.jbiom ech.2019.04.016

30. Zhang X-F, Liu L, Wang B-B, Liu X, Li P. Evidence for kinesio taping in management of myofascial pain syndrome: A systematic review and meta-analysis. Clin Rehabil. 2019;33(5):865-874. doi:10.1177/026921 $\underline{5519826267}$
31. Saracoglu I, Emuk Y, Taspinar F. Does taping in addition to physiotherapy improve the outcomes in subacromial impingement syndrome? A systematic review. Physiother Theory Pract. 2018;34(4):251-263. $\underline{\mathrm{d}}$ oi:10.1080/09593985.2017.1400138

32. Li Y, Yin Y, Jia G, Chen H, Yu L, Wu D. Effects of kinesiotape on pain and disability in individuals with chronic low back pain: A systematic review and metaanalysis of randomized controlled trials. Clin Rehabil. 2019;33(4):596-606. doi:10.1177/0269215518817804

33. Nelson NL. Kinesio taping for chronic low back pain: A systematic review. J Bodyw Mov Ther. 2016;20(3):672-681. doi:10.1016/i.jbmt.2016.04.018

34. Ramírez-Vélez R, Hormazábal-Aguayo I, Izquierdo M, González-Ruíz K, Correa-Bautista JE, GarcíaHermoso A. Effects of kinesio taping alone versus sham taping in individuals with musculoskeletal conditions after intervention for at least one week: A systematic review and meta-analysis. Physiotherapy. 2019;105(4):412-420. doi:10.1016/j.physio.2019.04.00 1

35. Luz Júnior MAD, Almeida MOD, Santos RS, Civile VT, Costa LOP. Effectiveness of kinesio taping in patients with chronic nonspecific low back pain: A systematic review with meta-analysis. Spine. 2019;44(1):68-78. doi:10.1097/brs.0000000000002756

36. Al-Subahi M, Alayat M, Alshehri MA, et al. The effectiveness of physiotherapy interventions for sacroiliac joint dysfunction: A systematic review. J Phys Ther Sci. 2017;29(9):1689-1694. doi:10.1589/jpt s.29.1689

37. Lin S, Zhu B, Huang G, Wang C, Zeng Q, Zhang S. Short-term effect of kinesiotaping on chronic nonspecific low back pain and disability: A metaanalysis of randomized controlled trials. Phys Ther. 2020;100(2):238-254. doi:10.1093/ptj/pzz163

38. Logan CA, Bhashyam AR, Tisosky AJ, et al. Systematic review of the effect of taping techniques on patellofemoral pain syndrome. Sports Health. 2017;9(5):456-461. doi:10.1177/1941738117710938

39. Cheatham SW, Stull KR, Ambler-Wright T. Roller massage: survey of physical therapy professionals and a commentary on clinical standards- part ii. Int J Sports Phys Ther. 2018;13(5):920-930. doi:10.26603/ij spt20180920

40. Cheatham SW. Roller Massage: A Descriptive Survey of Allied Health Professionals. J Sport Rehabil. 2019;28(6):640-649. doi:10.1123/jsr.2017-0366 
41. Whitaker C, Stevelink S, Fear N. The use of facebook in recruiting participants for health research purposes: A systematic review. J Med Internet Res. 2017;19(8):e290. doi:10.2196/jmir.7071

42. Dunne S, Cummins NM, Hannigan A, Shannon B, Dunne C, Cullen W. A method for the design and development of medical or health care information websites to optimize search engine results page rankings on Google. J Med Internet Res. 2013;15(8):e183. doi:10.2196/imir.2632

43. Cheatham SW, Stull KR. Knowledge of selfmyofascial release among allied health students in the United States: A descriptive survey. J Bodyw Mov Ther. 2018;22(3):713-717. doi:10.1016/i.jbmt.2018.0 $\underline{1.015}$

44. Cheatham SW, Baker RT, Larkin L, Baker J, Casanova M. Instrument assisted soft-tissue mobilization: A survey of practice patterns among allied health professionals. J Athl Train. 2020.

45. Camacho MA, Herrera E, Barela JA, et al. Kinesiotaping diminishes delayed muscle soreness but does not improve muscular performance. Int $J$ Sports Med. 2020;41(9):596-602.

46. Kirmizigil B, Chauchat JR, Yalciner O, et al. The effectiveness of kinesio taping in recovering from delayed onset muscle soreness: A cross-over study. J Sport Rehabil. 2019:1-28.

47. Hazar Kanik Z, Citaker S, Yilmaz Demirtas C, Celik Bukan N, Celik B, Gunaydin G. Effects of kinesio taping on the relief of delayed onset muscle soreness: A randomized, placebo-controlled trial. J Sport Rehabil. 2019;28(8):781-786. doi:10.1123/jsr.2018-00 $\underline{40}$

48. Lee YS, Bae SH, Hwang JA, Kim KY. The effects of kinesio taping on architecture, strength and pain of muscles in delayed onset muscle soreness of biceps brachii. J Phys Ther Sci. 2015;27(2):457-459. doi:10.15 89/ipts.27.457

49. Hadamus A, Grabowicz M, Wąsowski P, Mosiołek A, Boguszewski D, Białoszewski D. Assessment of the impact of kinesiology taping application versus placebo taping on the knee joint position sense. preliminary report. Ortop Traumatol Rehabil. 2018;20(2):139-148. doi:10.5604/01.3001.0012.0425

50. Torres R, Trindade R, Gonçalves RS. The effect of kinesiology tape on knee proprioception in healthy subjects. J Bodyw Mov Ther. 2016;20(4):857-862. doi:1 0.1016/j.jbmt.2016.02.009
51. Bischoff L, Babisch C, Babisch J, et al. Effects on proprioception by kinesio taping of the knee after anterior cruciate ligament rupture. Eur J Orthop Surg Traumatol. 2018;28(6):1157-1164. doi:10.1007/s0059 0-018-2167-1

52. Hosp S, Csapo R, Heinrich D, et al. Does Kinesiology tape counter exercise-related impairments of balance in the elderly? Gait Posture. 2018;62:167-172.

53. Liu K, Duan Z, Chen L, et al. Short-term effect of different taping methods on local skin temperature in healthy adults. Front Physiol. 2020;11:488. doi:10.338 9/fphys.2020.00488

54. Slomka B, Rongies W, Ruszczuk P, et al. Shortterm effect of kinesiology taping on temperature distribution at the site of application. Research in Sports Medicine. 2018;26(3):365-380. doi:10.1080/154 $\underline{38627.2018 .1447468}$

55. Yang JM, Lee JH. Is kinesio taping to generate skin convolutions effective for increasing local blood circulation? Med Sci Monit. 2018;24:288-293.

56. Hörmann J, Vach W, Jakob M, Seghers S, Saxer F. Kinesiotaping for postoperative oedema - what is the evidence? A systematic review. BMC Sports Sci Med Rehabil. 2020;12(1):14. doi:10.1186/s13102-020-0016 $\underline{2-3}$

57. Banerjee G, Briggs M, Johnson MI. The immediate effects of kinesiology taping on cutaneous blood flow in healthy humans under resting conditions: A randomised controlled repeated-measures laboratory study. Claydon-Mueller LS, ed. PLoS ONE. 2020;15(2):e0229386. doi:10.1371/journal.pone.0229 $\underline{386}$

58. Cimino SR, Beaudette SM, Brown SHM. Kinesio taping influences the mechanical behaviour of the skin of the low back: A possible pathway for functionally relevant effects. J Biomech. 2018;67:150-156. doi:10.1016/i.jbiomech.2017.12.005

59. Pamuk U, Yucesoy CA. MRI analyses show that kinesio taping affects much more than just the targeted superficial tissues and causes heterogeneous deformations within the whole limb. J Biomech. 2015;48(16):4262-4270. doi:10.1016/j.jbiomech.201 $\underline{5.10 .036}$

60. Mak DN-T, Au IP-H, Chan M, et al. Placebo effect of facilitatory Kinesio tape on muscle activity and muscle strength. Physiother Theory Pract. 2019;35(2):157-162. doi:10.1080/09593985.2018.1441 $\underline{936}$ 
61. MacPhail AJC, Au IP-H, Chan M, et al. Type effect of inhibitory KT tape on measured vs. perceived maximal grip strength. J Bodyw Mov Ther. 2018;22(3):639-642. doi:10.1016/j.jbmt.2017.10.011

62. Cai C, Au IPH, An W, Cheung RTH. Facilitatory and inhibitory effects of Kinesio tape: Fact or fad? J Sci Med Sport. 2016;19(2):109-112. doi:10.1016/i.jsam s.2015.01.010

63. Zhang S, Fu W, Pan J, Wang L, Xia R, Liu Y. Acute effects of Kinesio taping on muscle strength and fatigue in the forearm of tennis players. J Sci Med Sport. 2016;19(6):459-464. doi:10.1016/j.jsams.2015.0 $\underline{7.012}$

64. de Freitas FS, Brown LE, Gomes WA, Behm DG, Marchetti PH. NO effect of kinesiology tape on passive tension, strength or quadriceps muscle activation of during maximal voluntary isometric contractions in resistance trained men. Int J Sports Phys Ther. 2018;13(4):661-667. doi:10.26603/ijspt201 $\underline{80661}$

65. Poon KY, Li SM, Roper MG, Wong MKM, Wong O, Cheung RTH. Kinesiology tape does not facilitate muscle performance: A deceptive controlled trial. Man Ther. 2015;20(1):130-133. doi:10.1016/i.math.20 $\underline{14.07 .013}$

66. Korman P, Straburzyńska-Lupa A, Rutkowski R, et al. Kinesio taping does not alter quadriceps isokinetic strength and power in healthy nonathletic men: A prospective crossover study. Biomed Res Int. 2015;2015:626257. doi:10.1155/2015/626257

67. Cheung RTH, Yau QKC, Wong K, et al. Kinesiology tape does not promote vertical jumping performance: A deceptive crossover trial. Man Ther. 2016;21:89-93. doi:10.1016/j.math.2015.06.001

68. Au IPH, Fan PCP, Lee WY, et al. Effects of kinesio tape in individuals with lateral epicondylitis: A deceptive crossover trial. Physiother Theory Pract. 2017;33(12):914-919. doi:10.1080/09593985.2017.135 $\underline{9871}$

69. Chang H-Y, Wang C-H, Chou K-Y, Cheng S-C. Could forearm kinesio taping improve strength, force sense, and pain in baseball pitchers with medial epicondylitis? Clin J Sport Med. 2012;22(4):327-333. d oi:10.1097/jsm.0b013e318254d7cd

70. Cho Y-T, Hsu W-Y, Lin L-F, Lin Y-N. Kinesio taping reduces elbow pain during resisted wrist extension in patients with chronic lateral epicondylitis: A randomized, double-blinded, crossover study. BMC Musculoskelet Disord. 2018;19(1):193. doi:10.1186/s12891-018-2118-3
71. Luz Júnior MA, Sousa MV, Neves LAFS, Cezar AAC, Costa LOP. Kinesio taping ${ }^{\circledR}$ is not better than placebo in reducing pain and disability in patients with chronic non-specific low back pain: A randomized controlled trial. Braz J Phys Ther. 2015;19(6):482-490. doi:10.1590/bjpt-rbf.2014.0128

72. de Ru E, Mikołajewska E. Skin irritation incidence following kinesiology tape use in patients with neurological disorders: Multicenter observation. Ann Acad Med Siles. 2017;71:7-13. doi:10.18794/aams/653 $\underline{22}$

73. Mikołajewska E. Side effects of kinesiotaping own observations [Skutki uboczne kinesiotapingu obserwacje własne (artykuł w j. angioelskim)] J Health Sci. 2011;1(4):93-99.

74. Gatt M, Willis S, Leuschner S. A meta-analysis of the effectiveness and safety of kinesiology taping in the management of cancer-related lymphoedema. Eur J Cancer Care. 2017;26(5):e12510. doi:10.1111/ecc.125 $\underline{10}$

75. Martins J de C, Aguiar SS, Fabro EAN, et al. Safety and tolerability of Kinesio ${ }^{\circledR}$ Taping in patients with arm lymphedema: Medical device clinical study. Support Care Cancer. 2016;24(3):1119-1124. doi:10.10 07/s00520-015-2874-7

76. López R, García-Muro San José F. Skin reactions after using kinesio tex tape. a pilot study. Paper presented at the: 30th Annual Research Symposium Kinesio Taping Association International; November 10, 2015; Tokyo, Japan.

77. Andrýsková A, Lee J-H. The Guidelines for application of kinesiology tape for prevention and treatment of sports injuries. Healthcare. 2020;8(2):144. doi:10.3390/healthcare8020144

78. Djordjevic OC, Vukicevic D, Katunac L, Jovic S. Mobilization with movement and kinesiotaping compared with a supervised exercise program for painful shoulder: Results of a clinical trial. $J$ Manipulative Physiol Ther. 2012;35(6):454-463. doi:1 0.1016/j.jmpt.2012.07.006

79. Wu W-T, Hong C-Z, Chou L-W. The kinesio taping method for myofascial pain control. Evid Based Complement Altern Med. 2015;2015:950519-950519.

80. Banerjee G, Rebanks J, Briggs M, Johnson MI. Kinesiology taping as an adjunct for pain management in cancer? BMJ Case Reports. 2016;2016:bcr2016216439. doi:10.1136/bcr-2016-216 $\underline{439}$ 
81. Banerjee G, Rose A, Briggs M, Johnson MI. Could kinesiology taping help mitigate pain, breathlessness and abdominal-related symptoms in cancer? BMJ Case Reports. 2017;2017:bcr2016216695. doi:10.1136/ bcr-2016-216695

82. Cavaleri R, Thapa T, Beckenkamp PR, Chipchase LS. The influence of kinesiology tape colour on performance and corticomotor activity in healthy adults: A randomised crossover controlled trial. BMC Sports Sci Med Rehabil. 2018;10(1):17. doi:10.1186/s13 102-018-0106-4

83. Boonkerd C, Limroongreungrat W. Elastic therapeutic tape: Do they have the same material properties? J Phys Ther Sci. 2016;28(4):1303-1306. do i:10.1589/jpts.28.1303

84. de Jesus JF, Franco YR, Nannini SB, et al. The effects of varied tensions of kinesiology taping on quadriceps strength and lower limb function. Int $J$ Sports Phys Ther. 2017;12(1):85-93.

85. Lemos TV, Júnior JR de S, Santos MGR II, Rosa MMN, Silva LGC da, Matheus JPC. Kinesio Taping effects with different directions and tensions on strength and range of movement of the knee: A randomized controlled trial. Braz J Phys Ther. 2018;22(4):283-290. doi:10.1016/i.bjpt.2018.04.001

86. Chen Y-S, Tseng W-C, Chen C-H, Bezerra P, Ye X. Acute effects of kinesiology tape tension on soleus muscle h-reflex modulations during lying and standing postures. Tremblay F, ed. PLoS ONE. 2020;15(7):e0236587. doi:10.1371/journal.pone.02365 $\underline{87}$

87. Yoosefinejad AK, Motealleh A, Abbasalipur S, Shahroei M, Sobhani S. Can inhibitory and facilitatory kinesiotaping techniques affect motor neuron excitability? A randomized cross-over trial. J Bodyw Mov Ther. 2017;21(2):234-239. doi:10.1016/i.jb mt.2016.06.011

88. Serrão JC, Mezêncio B, Claudino JG, et al. Effect of 3 different applications of kinesio taping denko ${ }^{\circledR}$ on electromyographic activity: Inhibition or facilitation of the quadriceps of males during squat exercise. $J$ Sports Sci Med. 2016;15(3):403-409.

89. Bagheri R, Pourahmadi MR, Sarmadi AR, Takamjani IE, Torkaman G, Fazeli SH. What is the effect and mechanism of kinesiology tape on muscle activity? J Bodyw Mov Ther. 2018;22(2):266-275. doi:1 0.1016/j.jbmt.2017.06.018

90. Sanzo P. The Effect of taping on isometric shoulder strength and emg activity of the shoulder during functional movements. Int J Prev Treat. $2017 ; 6: 28-33$.
91. Grześkowiak M, Krawiecki Z, Łabędź W, Kaczmarczyk J, Lewandowski J, Łochyński D. Shortterm effects of kinesio taping ${ }^{\circledR}$ on electromyographic characteristics of paraspinal muscles, pain, and disability in patients with lumbar disk herniation. $J$ Sport Rehabil. 2019;28(5):402-412. doi:10.1123/jsr.20 17-0086

92. Pires LG, Padula RS, Junior M, et al. Can kinesio taping ${ }^{\circledR}$ influence the electromyographic signal intensity of trunk extensor muscles in patients with chronic low back pain? arandomized controlled trial. Braz J Phys Ther. 2019;24(6):539-549.

93. Velasco-Roldán O, Riquelme I, Ferragut-Garcías A, Heredia-Rizo AM, Rodríguez-Blanco C, OlivaPascual-Vaca Á. Immediate and short-term effects of kinesio taping tightness in mechanical low back pain: A randomized controlled trial. $P M R$.

2018;10(1):28-35. doi:10.1016/j.pmrj.2017.05.003

94. Wilson V, Douris P, Fukuroku T, et al. The immediate and long-term effects of kinesiotape ${ }^{\circledR}$ on balance and functional performance. Int J Sports Phys Ther. 2016;11(2):247-253.

95. Rasti ZA, Shamsoddini A. The Short-term and long-term effects of kinesio taping on the pain, range of motion and disability of neck in patients with myofascial pain syndrome: A randomized clinical trial. Trauma Mon. 2018;24(1):1-6. doi:10.5812/traum amon.69226

96. Noguera-Iturbe Y, Martínez-Gramage J, Montañez-Aguilera FJ, Casaña J, Lisón JF. Short-term effects of kinesio taping in the treatment of latent and active upper trapezius trigger points: Two prospective, randomized, sham-controlled trials. Sci Rep. 2019;9(1):14478. doi:10.1038/s41598-019-5114 $\underline{6-4}$

97. Halski T, Ptaszkowski K, Słupska L, et al. Shortterm effects of kinesio taping and cross taping application in the treatment of latent upper trapezius trigger points: A prospective, single-blind, randomized, sham-controlled trial. Evid Based Complement Alternat Med. 2015;2015:191925. doi:1 $\underline{0.1155 / 2015 / 191925}$

98. Mohamadi M, Piroozi S, Rashidi I, Hosseinifard S. Friction massage versus kinesiotaping for short-term management of latent trigger points in the upper trapezius: A randomized controlled trial. Chiropr Man Therap. 2017;25(1):25. doi:10.1186/s12998-017-015 $\underline{6-9}$

99. Jackson K, Simon JE, Docherty CL. Extended use of kinesiology tape and balance in participants with chronic ankle instability. J Athl Train. 2016;51(1):16-21. doi:10.4085/1062-6050-51.2.03 
100. Kaya DO, Baltaci G, Toprak U, Atay AO. The clinical and sonographic effects of kinesiotaping and exercise in comparison with manual therapy and exercise for patients with subacromial impingement syndrome: A preliminary trial. J Manip Physiol Therapeut. 2014;37(6):422-432. doi:10.1016/j.jmpt.20 14.03 .004

101. Mohamed SHP, Alatawi SF. comparison of kinesio taping and manual therapy with supervised exercise therapy for the treatment of shoulder impingement syndrome. Int J Physiother. 2019;6(5). $\underline{\mathrm{d}}$ oi:10.15621/ijphy/2019/v6i5/186839

102. Roberts S, Ramklass S, Joubert R. Kinesio Taping ${ }^{\circledR}$ of the metacarpophalangeal joints and its effect on pain and hand function in individuals with rheumatoid arthritis. South African J Physiother. 2016;72(1):314-314. doi:10.4102/sajp.v72i1.314

103. Donec V, Kubilius R. The effectiveness of kinesio taping ${ }^{\circledR}$ for pain management in knee osteoarthritis: A randomized, double-blind, controlled clinical trial. Therapeutic Advances in Musculoskeletal. 2019;11(1759720):19869135. doi:10.1177/1759720x19 $\underline{869135}$

104. Windisch C, Brodt S, Röhner E, Matziolis G. Effects of Kinesio taping compared to arterio-venous Impulse System ${ }^{\mathrm{TM}}$ on limb swelling and skin temperature after total knee arthroplasty. Int Orthop. 2017;41(2):301-307. doi:10.1007/s00264-016-3295-Z

105. Tantawy SA, Abdelbasset WK, Nambi G, Kamel DM. Comparative study between the effects of kinesio taping and pressure garment on secondary upper extremity lymphedema and quality of life following mastectomy: A randomized controlled trial. Int Cancer Ther. 2019;18:1534735419847276. doi:10.117 7/1534735419847276

106. Farquharson C, Greig M. temporal pattern of kinesiology tape efficacy on hamstring extensibility. Int J Sports Phys Ther. 2015;10(7):984-991.
107. de Jesus JF, Franco YRDS, Nannini SB, et al. The effects of varied tensions of kinesiology taping on quadriceps strength and lower limb function. Int J Sports Phys Ther. 2017;12(1):85-93.

108. Cheatham SW, Kolber MJ, Cain M. Comparison of video-guided, live instructed, and self-guided foam roll interventions on knee joint range of motion and pressure pain threshold: A randomized controlled trial. Int J Sports Phys Ther. 2017;12(2):242-249.

109. Selva F, Pardo A, Aguado X, Montava I, GilSantos L, Barrios C. A study of reproducibility of kinesiology tape applications: Review, reliability and validity. BMC Musculoskelet Disord. 2019;20(1):153. $\underline{\mathrm{d}}$ oi:10.1186/s12891-019-2533-0

110. Matheus JPC, Zille RR, Gomide Matheus LB, Lemos TV, Carregaro RL, Shimano AC. Comparison of the mechanical properties of therapeutic elastic tapes used in sports and clinical practice. Phys Ther Sport. 2017;24:74-78. doi:10.1016/j.ptsp.2016.08.014

111. Choi I-R, Lee J-H. Effect of kinesiology tape application direction on quadriceps strength. Medicine. 2018;97(24):e11038. doi:10.1097/md.00000 $\underline{00000011038}$

112. Magalhães IEJ, Mezzarane RA, Carregaro RL. Therapeutic elastic tapes applied in different directions over the triceps surae do not modulate reflex excitability of the soleus muscle. J Sport Rehabil. 2020;30(1):22-29. doi:10.1123/jsr.2018-0435

113. Kim K-M, Davis B, Hertel J, Hart J. Effects of Kinesio taping in patients with quadriceps inhibition: A randomized, single-blinded study. Phys Ther Sport. 2017;24:67-73. doi:10.1016/j.ptsp.2016.08.015

114. Limmer M, Buck S, de Marées M, Roth R. Acute effects of kinesio taping on muscular strength and endurance parameters of the finger flexors in sport climbing: A randomised, controlled crossover trial. Eur J Sport Sci. 2020;20(4):427-436. doi:10.1080/1746 $\underline{1391.2019 .1633415}$ 